\title{
An Integrated Starter-Generator and Winding Configuration for Hybrid Vehicles
}

\author{
Darshan M Hosad ${ }^{1}$, M Chandana ${ }^{2}$, Bhaskar $\mathbf{R}^{3}$, Sharen Ranjit ${ }^{4}$ \\ Student, Electrical and Electronics, CMRIT, Bangalore, India ${ }^{1,2,3}$ \\ Asst Professor, Electrical and Electronics, CMRIT, Bangalore, India ${ }^{4}$
}

\begin{abstract}
This paper comprises of constructing variants, the mounting details of ISG, advantages and benefits of ISG. The four major hardware components: an induction machine, a winding switching board, a motor controlling inverter/rectifier and a system control board. A different electrical machine type that could be used for ISG application, mentioning also some typical commercial available unit. Furthermore the paper gives idea about winding reconfiguration with the ability to externally switch the winding configuration for optimal performance.
\end{abstract}

Keywords: Hybrid Electric Vehicle, ISG, Winding Re-configuration, Hardware Build and Integration.

\section{INTRODUCTION}

Over the past decade the automotive industry has been investigating alternatives to traditional internal combustion engine for powered vehicles so as to boost their fuel efficiency and to scale back their greenhouse gas emissions.

This challenge of fuel economy standards is promoting optimized and generally novel vehicle power train architectures that combine the conventional internal combustion engine (ICE) with numerous styles of electrical drives. The different types of the hybrid electrical vehicles (HEV) are real competitors of the classical ICE driven cars.

Additional factors, including change in voltage standards (from twelve to forty two VDC), the presence of high voltage, high power battery sources, and the trend toward a lot of electrically driven automobile parts call for new innovations and implementations to replace old technologies. The engine starter motor and the alternator are electrical components that have received significant attention. The drive is to combine these separate elements into a single unit that performs the functions of both.

In 2002 automotive manufacturers have announced plans to improve passenger vehicle fuel economy with $25 \%$ or more by year 2005.Today hybridized power trains are already commercially on the market. In such sort of product applications, like the integrated starter-generator (ISG) are rising with accompany to benefit hybrid electrical vehicles however with very little or no cost/performance penalties.

The ISG replaces the traditional starter motor and the alternator, besides its two major function as a starter and generator it also provides an auxiliary function as a convenient vehicle automatic start-stop system for improved performance. When the vehicle is in standstill in traffic and want to accelerate instantly, it automatically restarts using ISG very rapidly when gas pedal is pressed and when the vehicle want to attain the idle speed then the combustion process for instant ignition is initiated. During braking the ISG converts the kinetic energy of the vehicle into electrical and fed to the battery. The methodology of ISG system is interfaced with $220 \mathrm{~V}$ DC power source. The ISG is to develop a minimum of $30 \mathrm{Nm}$ of torque at standstill, accelerate to $2500 \mathrm{rpm}$ at a constant power of one kilowatt, and switch into generating mode to generate one kilowatt of $200 \mathrm{~V}$ DC power at 3000rpm with an efficiency of at least $75 \%$.

\section{HYBRID ELECTRIC VEHICLE}

One of the aims of the automotive business is a more economical use of energy in a vehicle. HEVs are potential candidates to reduce both consumption and emissions. Hybrid power trains use a standard ICE together with an electrical motor, a battery, and an electronic controller. HEVs have 2 basic configurations: series and parallel hybrids (Fig 1).

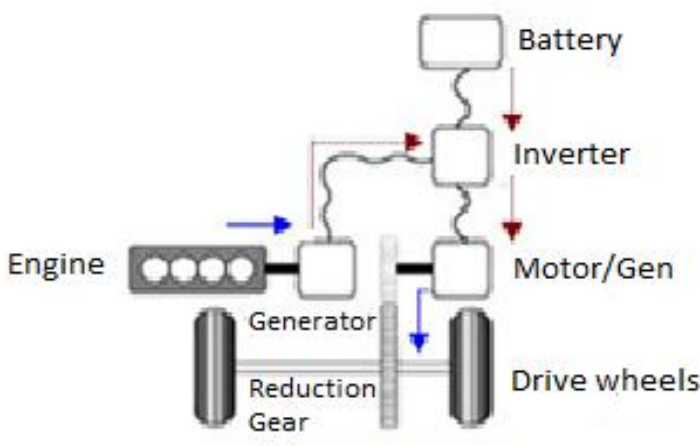

Series Configuration 
ISO 3297:2007 Certified

Vol. 5, Issue 2, February 2017

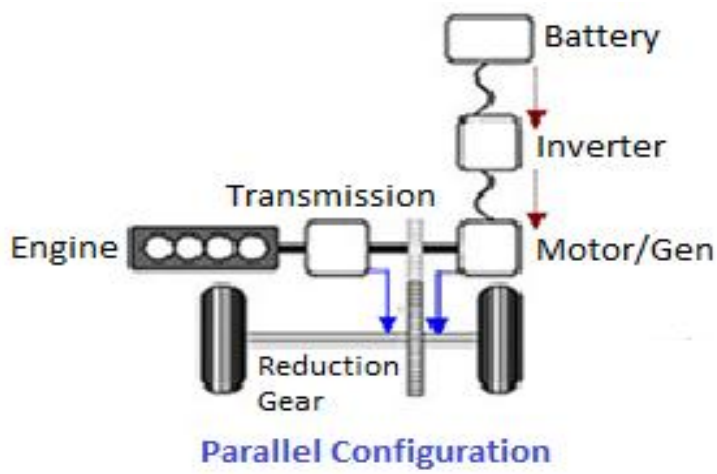

Fig.1. The basic configuration of HEVs

In the series variant, the ICE is employed to drive an alternator to generate electricity that is then stored in a battery system or sent directly to the electrical motor, which powers the wheels. The engine isn't supplying power directly to the wheels. The efficiency of the engine is maximized as a result of it operates in a narrow range of speeds. The parallel hybrid has 2 power ways, so either the IEC or the electrical motor (or both) are often used to power the wheels directly. Just like the series configuration it will operate in zero-emission mode (power equipped only via the electrical motor). At cruising speeds the IEC is the only power source, however under high load (during acceleration and hill climbing) both ICE and motor can operate together, with the electrical motor boosting the low speed torque of the ICE serving to save 10 to $15 \%$ in fuel prices [1]. While the parallel configuration might not match the efficiency of a series hybrid system, its typically higher power output is better matched to the practical demands of everyday motoring [2].

Since the electric motor and the battery source provide extra power to the ICE, the fuel consumption is reduced without disturbing power output. In order to further save fuel, the engine is automatically shutdown when the vehicle comes to stand still and starts again automatically when the accelerator is pressed. The battery is recharged from the energy obtained during the regenerative braking, relieving the ICE from its work and reducing the fuel consumption. A hybrid vehicle is self-sufficient, and need not to be plugged in and charged throughout.

The first hybrid passenger vehicle in the world is Toyota Prius. Which is running on road since 1998. The advanced model of this system achieves comparatively twice the fuel efficiency of traditional gasoline engine [3]. The simplified version of the hybrid power trains is called the "mild hybrid", where ISG is used instead of an electric propulsion motor.ISG alone cannot move the car but it can assist the propulsion and get back the energy through regenerative braking. The mild hybrid are basically operated same as the full hybrid, but mild hybrid will be having smaller battery than the full hybrid and cannot operate on the battery power alone. The advantage of mild
HEV system is its low cost compared to the full HEV system. A typical mild hybrid vehicle system's configuration is given in Fig.2

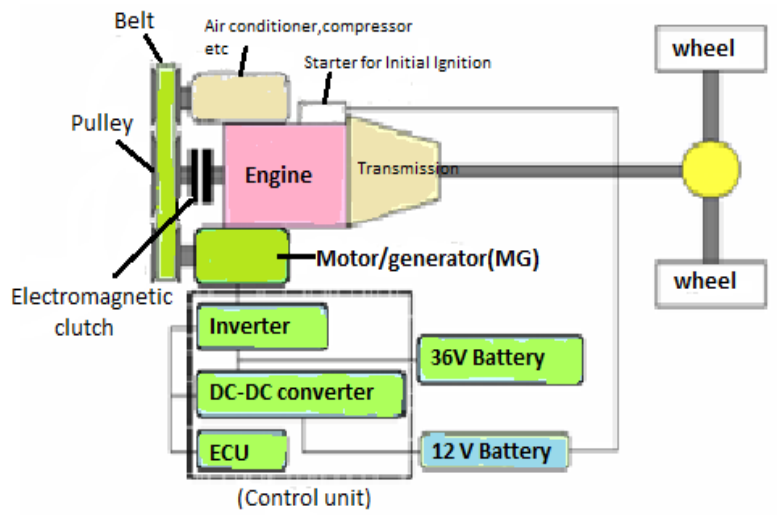

Fig.2. Mild hybrid vehicle system

\section{THE INTEGRATED STARTER GENERATOR SYSTEM}

Schematic of ISG system is shown in Fig.3

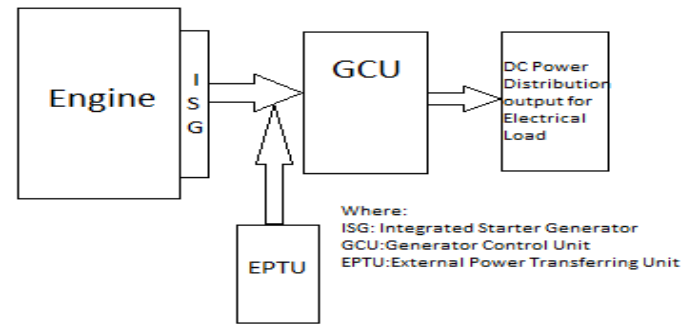

Fig.3 Schematic of Integrated Starter Generator (ISG) system

Typical mounting representation of ISG:

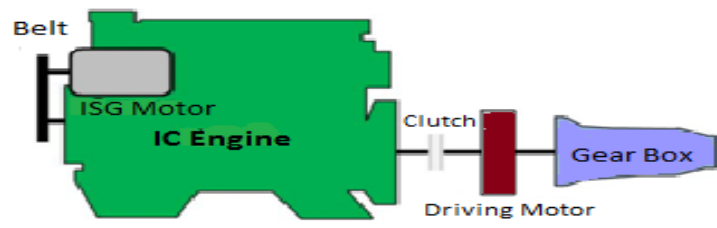

Fig.4 General mounting representation of ISG

In many cases ISG is sandwiched between the engine and transmission shown in Fig.5

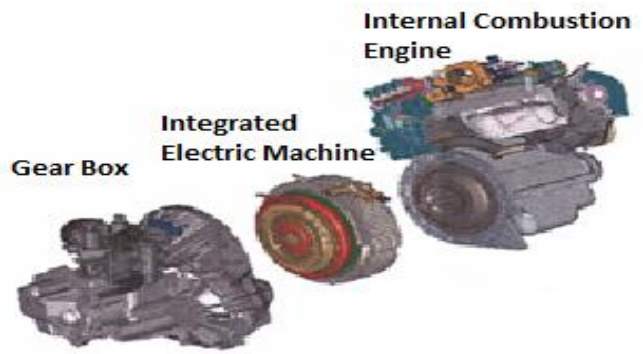

Fig.5 A possible place of the ISG in a HEV power train 
The ISG has 3 basic functions: start-stop, power generation, power assistance. The ISG led ICE to turn off and save energy (and save fuel) at stops and instantly restart upon pressing the gas pedal. Hence instead of using fuel at idling speed, for example when the vehicle is in stand still in traffic, the engine of vehicle with ISG switches off. When the traffic light turns green and the driver accelerate the vehicle the ISG starts instantly by helping the vehicle to accelerate. Once the speed exceeds the certain permissible limit, the ISG drive power is turned off. The driver will not notice since ISG system starts ICE independently. The ISG will generate electric power to be stored in battery by using mechanical energy from the spinning crankshaft of the vehicle(running power generation mode).Addition to that ISG also acts as a retarding force to the crankshaft and regenerate power to fed back to battery, when releasing the accelerator and pressing the brake pedal(braking power generation mode).During the boost mode ISG support ICE by supplying additional power for instant acceleration.ISG remains active throughout the driving process, for an instant while overtaking the other vehicle which requires extra power which is provided by ISG.

\section{Advantages of ISG [4]:}

- Since ICE is combined with electric motor and the ISG system augment power of existing engines by providing electric "motor assist", or enabling a "startstop" for a smaller ICE can be used without affecting system performance.

- The start-stop operation, recuperative braking capacity, its higher voltage and increased size makes the ISG more efficient than a traditional generator, resulting $20 \%$ reduction in the fuel consumption.

- Due to use of ISG, the fuel consumption is reduced and even lower emissions of ICE are achieved, especially during the start period.

- Instead of idling the engine shuts down with the use of ISG. For people who drive in urban area there is clear evidence of this benefit, because the ICE is not used when vehicle is stand still.

- There is reduction in noise and vibration and hence increasing the operation comfort

- There is no wear and tear of the components of the ISG because it is brushless design system

- The ISG has the capability to smoothing torque of the driveline. By applying an proper damping control algorithm also power train oscillations and vibration can be neutralized.

- It is very cost-efficient system ,because ISG can be integrated with any of the actual car model, therefore there is no need to develop a new car model

- Since the design of ISG have influence on cold starting requirement, hence it can also start ICE under low temperature.

The main drawbacks of the ISGs is that they require specialized power system. The design has been a great challenge for the experts the requirements of ISG drives are as follows:

- At most unfavorable operating condition it requires high starting torque.

- It requires wide range of speed in generator mode.

- Higher efficiency in wide speed range(600-8000rpm)

- In crankshaft mounted system Vibrations will be $20 \mathrm{~g}$

- Life Cycle of 250000 stop/start cycles in ten years

- Temperature range of $-30 \mathrm{C}$ to $115 \mathrm{C},+180 \mathrm{C}$ under hood

The types of ISG presently being used: the belt driven (Fig6.b) and directly being connected to crankshaft between the engine and gearbox (Fig 6.c). The two ISG are being compared with independent starter and generator type are given (Fig 6.a) .In the figure it is seen that the crankshaft ISG is mounted behind the engine, where clutch or torque converter is already being set. This reduces the cost and complexity of belt dive, but it requires extra weight of copper and iron of the crankshaft ISG.

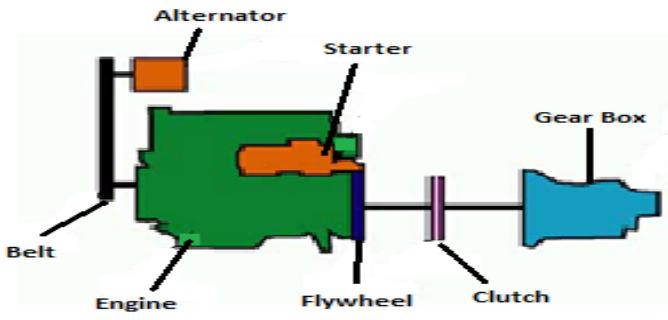

a) Independent starter and generator

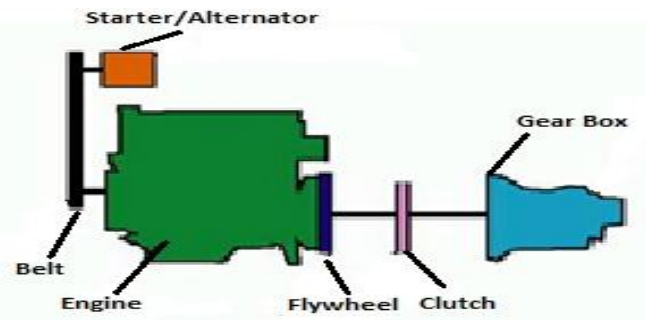

b) Belt driven ISG

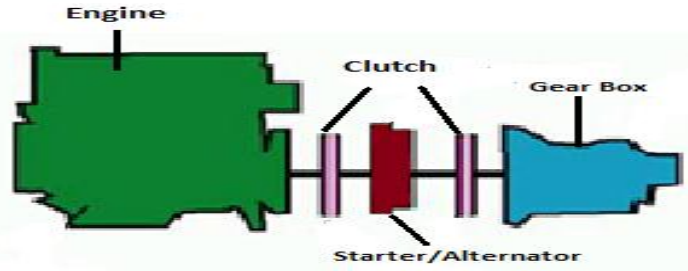

c) Crankshaft ISG

Fig 6 Starter generator constructions

\section{WINDING RECONFIGURATION}

ISG Variants:

Depending upon the requirement of ICE and vehicle's electrical system various electrical machines can be proposed for the operation of ISG: Induction machine (IM), permanent magnet synchronous (PMSM), brushless 
Vol. 5, Issue 2, February 2017

dc (BDCM), and Variable reluctance machines (VRM) [5][6][7]. Among all the IM and PMSM are the current competitors, but for future improved electrical machine must be taken into consideration.

\section{THEORECTCAL DESIGN:}

As discussed before ISG requires wide speed range, In order to facilitate that the pole number of stator of the Induction Machine is changed from 8 to 4 and controlling the motor with voltage/frequency controller via inverter. The machine selected for this purpose is conventional lap winding squirrel-cage induction machine. It is being chosen in order to lessen the system cost and to facilitate change. The machine respect to NEMA 56 frame size standards, and having a stack length of $8.8 \mathrm{~cm}$. This size is chosen so that it facilitate sufficient core and iron supply for required power and torque. The cross sectional diagram of machine stator and rotor is shown in Fig 7.

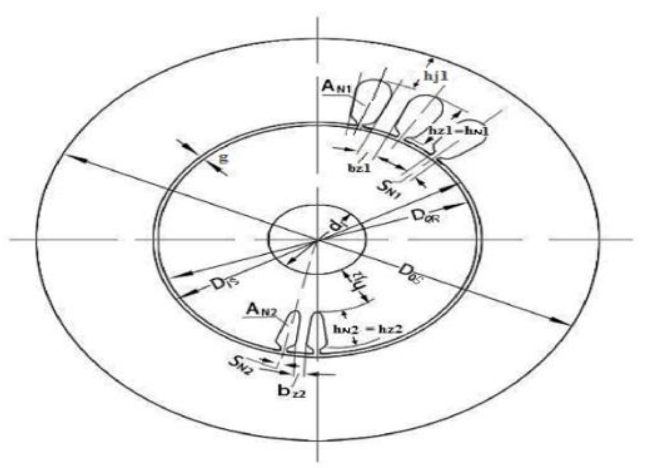

Fig.7 Cross-sectional diagram of Induction machine

The winding reconfiguration of the machine is being done by rewinding the stator for both 4 and 8 pole connections and bringing a 48 winding which leads to interface the switch network but no change is being done in the rotor. Firstly the machine is designed as an 8-pole machine in the startup in order to increase the starting and low-speed torque, and later is being switched to 4-pole at higher speed so as to maximize the efficiency of the machine. At stand still the machine is operated as 8-pole and having a frequency of $27 \mathrm{~Hz}$. The line-to-line voltage of $121 \mathrm{Vrms}$ is provided by the power inverter. The calculated starting torque during this operation is $30 \mathrm{Nm}$. The drive is then increased from low frequency to a frequency of $50 \mathrm{~Hz}$ in order to accelerate machine and its load. The inverter is designed to give out $1 \mathrm{~kW}$ of constant power to the system. Once the shaft reaches its permissible speed of $750 \mathrm{rpm}$, the machine is switched to 4-pole form 8-pole which causes the increasing in speed to $1500 \mathrm{rpm}$. The parameter and specification list for induction machine is given in Table1.

The inverter drive frequency is increased form $50 \mathrm{~Hz}$ to $75 \mathrm{~Hz}$ once again in order to increase the speed beyond 1500rpm which will be around 2250rpm. Due to lack of EMF developed above $1500 \mathrm{rpm}$, the V/f ratio is set to compensate field weakening.
TABLE 1 Parameter and specification list for Induction Machine

\begin{tabular}{|l|}
\hline Stator: \\
\hline One sided air gap $(\mathrm{g})=0.34375 \mathrm{~mm}$ \\
\hline Number of stator slots $(\mathrm{N} 1)=24$ slots \\
\hline Outer diameter of stator core $(\mathrm{Dos})=153.2 \mathrm{~mm}$ \\
\hline Number of poles $(\mathrm{p})=2$ poles \\
\hline Inner diameter of stator core $(\mathrm{Dis})=79.375 \mathrm{~mm}$ \\
\hline Axial length of stator core $(\mathrm{l})=88 \mathrm{~mm}$ \\
\hline Cross-section of one stator slot $(\mathrm{AN} 1)=78 \mathrm{~mm} 2$ \\
\hline Height of stator back iron $(\mathrm{hj} 1)=21 \mathrm{~mm}$ \\
\hline Height of one stator slot $(\mathrm{hN} 1=\mathrm{hz} 1)=14.9 \mathrm{~mm}$ \\
\hline Opening of stator slot $(\mathrm{SN} 1)=1.85 \mathrm{~mm}$ \\
\hline bz1 $=1.85 \mathrm{~mm}$ \\
\hline \\
\hline Rotor: \\
\hline Number of rotor slots $(\mathrm{N} 2)=34$ slots \\
\hline Outer diameter of rotor core $(\mathrm{Dor})=78.5 \mathrm{~mm}$ \\
\hline Cross section of one rotor slot $(\mathrm{AN} 2)=\mathrm{N} / \mathrm{A}$ \\
\hline Height of rotor back iron $(\mathrm{hj} 2)=14.5 \mathrm{~mm}$ \\
\hline Height of rotor slot (hN2 $=\mathrm{hz} 2)=14.5 \mathrm{~mm}$ \\
\hline Opening of rotor slot $(\mathrm{SN} 2)=\mathrm{N} / \mathrm{A}$ \\
\hline Inner diameter of rotor core $(\mathrm{di})=22 \mathrm{~mm}$ \\
\hline $\begin{array}{l}\text { Total winding turns }=400 \text { turns per phase with AWG } \\
\# 23\end{array}$ \\
\hline
\end{tabular}

The number of stator turns per phase $(\mathrm{N})$ is reduced by half in order accomplish back EMF and increase in torque output high speed [8][9][10].This increase in flux due to stator winding gives torque boost to the shaft output. After this reconfiguration of winding is done the frequency is increased to $100 \mathrm{~Hz}$ taking shaft speed from $2500 \mathrm{rpm}$ to $3000 \mathrm{rpm}$. The plot of change in frequency and change is shaft speed with respect to time is given in Fig.8 and Fig.9.

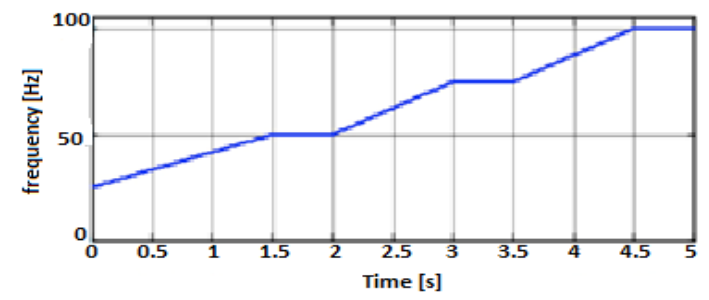

Fig.8 Drive control frequency during acceleration

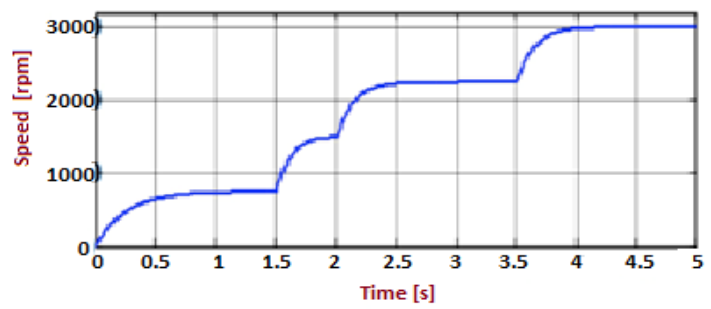

Fig.9 Shaft speed during acceleration with constant power load 
TABLE 2 Summary of Controlled Machine Acceleration

\begin{tabular}{|l|l|l|l|}
\hline $\begin{array}{l}\text { Speed } \\
(\mathrm{rpm})\end{array}$ & $\begin{array}{l}\text { Frequency } \\
(\mathrm{Hz})\end{array}$ & $\begin{array}{l}\text { Time } \\
(\mathrm{sec})\end{array}$ & $\begin{array}{l}\text { Winding } \\
\text { Configuration }\end{array}$ \\
\hline $0-750$ & $27-50$ & $0-1.5$ & 8-pole,N turns \\
\hline $750-1500$ & 50 & $1.5-2$ & 4-pole,N turns \\
\hline $1500-2250$ & $50-75$ & $2-3.5$ & 4-pole,N turns \\
\hline $2250-3000$ & $75-100$ & $3.5-5$ & 4-pole,N/2 turns \\
\hline
\end{tabular}

\section{HARDWARE BUILD AND INTEGRATION}

The four main components are integrated to form a complete system, they are induction machine, motor controlling inverter, winding switching board and the system microcontroller. The description of the components are given here.

\section{A. Induction Machine}

A Dayton 4B237 compressor-grade motor is required. It is rated for $3 \mathrm{H} . \mathrm{P}$ at $3500 \mathrm{rpm}$ and $60 \mathrm{~Hz}, 240 / 480$ volts AC, with a current of $8.5 \mathrm{amps}$. Additional specification are included in Table 1.

No-load and locked -rotor tests are carried out with a voltage of $240 \mathrm{~V} \mathrm{AC}, 60 \mathrm{~Hz}$ input. From this test data, the required winding specifications were calculated. The number of turns were found to be 400 turns per phase as per the calculations with AWG\#23 conductor.

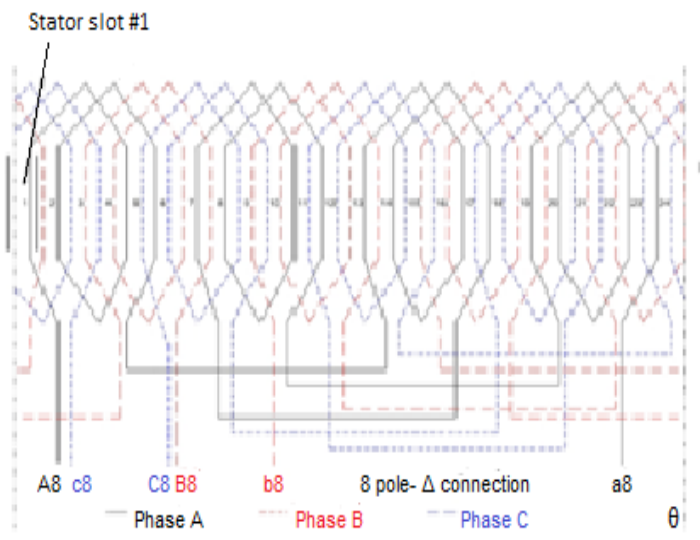

Fig.10 Eight pole delta winding connection diagram

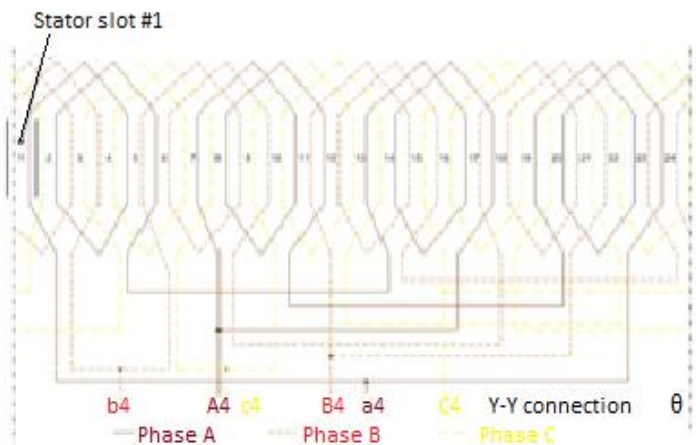

Fig.11 Four pole double wye winding connection diagram
The machine is constructed as 8-polr/4-pole machine with facilitate pole changing and winding switching. The machine were subjected to locked-rotor and no-load tests. The machine operation in 8-pole (delta),4-pole (double wye) and 4-pole(double wye) with half number of turns were tested and verified. Fig10 and 11 shown the double winding connection for 8-pole delta and 4-pole double wye configuration

\section{B. Winding Switching Board}

The 48 machine leads are connected to switching networks that has the winding reconfiguration. This board is being built from electrically actuated mechanical contactors. The signals established by the system microcontroller controls the switches. Fig.12 is the representation of winding switching configuration

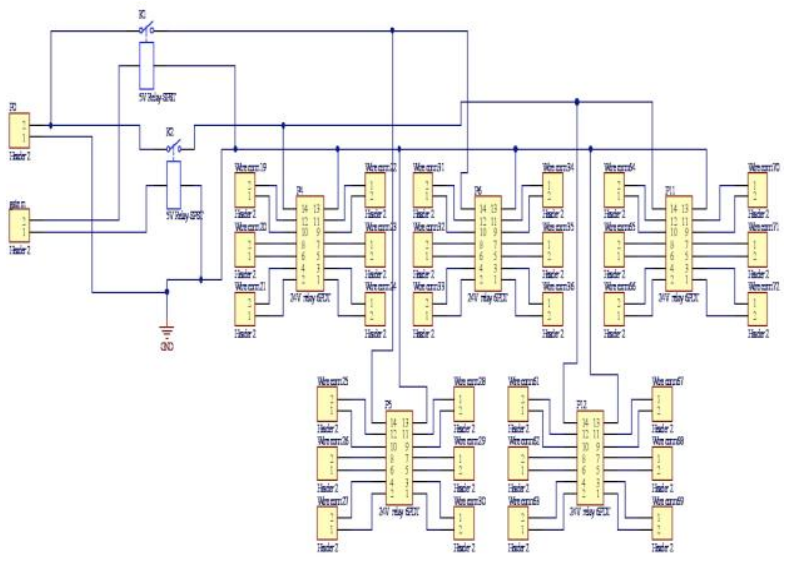

Fig.12 Diagram of winding switch network

\section{Motor Controlling Inverter}

The induction machine is controlled by an shelf inverter board. The uses IGBTs to implement the inverter bridge which provides PWM motor control waveform. The constant V/f control method is used for inverter PWM control. The microcontroller interfaces with inverter board to form correct waveform for machine during its operation. During a pre-specified speed of 2500rpm, the system switches from motoring to generating mode allowing it to act as a generator, It is coordinated by system controller. Phase lead provides quadrature excitation current to the machine which can be done by connecting the three 100microF capacitors across the machine input. The inverter operates in reverse as a controlled rectifier, regulating to generator output to $200 \mathrm{~V}$ DC.

\section{System Micro-Controller}

The micro-controller manages the overall system. The micro controller has the three main functions:

1. It sends signal to switch network to change the winding configuration.

2. In the inverter it control the IGBT gate drive during both motoring and generating operation.

3. It facilitate simpler interface for the user to on and off. 


\section{IJIREEICE \\ International Journal of Innovative Research in Electrical, Electronics, Instrumentation and Control Engineering \\ ISO 3297:2007 Certified}

Vol. 5, Issue 2, February 2017

The microcontroller and it circuitry are controlled through software algorithm loaded onto microcontroller using PC interface. Software perform the timing of the winding changes and PWM control of the machine. By sensing of output voltage and current on the inverter board speed is determined. From this information the microcontroller manages the system with no additional input from user.

\section{CONCLUSION}

Hybrid vehicles are arriving on the transportation field in order to reduce fuel consumption and limit the emission of green house gases. The technical and business consideration of hybrid vehicles are improved day by day. Hence specialists consider, that HEVs present economical solution for producing low consumption and low emission automobiles. Mild hybrid with ISG system are capable of providing engine cranking and acceleration assistance having many more benefits as improved fuel consumption, reduce emission of gas and improved performance

\section{ACKNOWLEDGEMENT}

The work was possible due to the support given by the Lectures of Electrical and Electronics Department, CMR Institute of Technology, Bangalore. A special regards to the lecture who helped in formatting the paper.

\section{REFERENCES}

[1] Marian P.Kazmierkowski, "Modern Electric, Hybrid Electric, and Fuel Cell Vehicles" IEEE Industrial Electronics Magazine 2010, pp. $75-75$

[2] Dettmer, R., "Hybrid Vigour," IET Journals \& Magazines, January 2001, pp. 25-28.

[3] Naritomo Higuchi, Hiroo Shimada, "Efficiency enhancement of a new two-motor hybrid system", World Electric Vehicle Symposium and Exhibition 2013, pp.1-11

[4] Shuangxia Niu, K.T Chau, J.Z Jiang, "A Permananent-magnet double-stator integrated-starter-generator for hybrid electric vehicles" IEEE Vehicles Power and Propulsion Conference 2008, pp-1-6

[5] Giuseppe Scarcella,Giacomo Scelba,Mario Cacciato, Andrea Spampinato, Mark M Harbaugh, "Vector Control Strategy for Multidirectional Power Flow in Integrated Multidrives, IEEE Transaction on Industry Application 2016,pp.4816-4826

[6] Ye Yuan, Yukun Sun, Yonhong Huang, "Design and analysis of bearingless flywheel motor specially for flywheel energy storage", IET Journals \& Magazines 2016, pp.66-68

[7] Tausif Husain,Iftekhar Hassan, Yilmaz Sozer, Iqbal Husain, Eduard Muljadi, "Winding schemes forwide constant power range ofdouble stator transverse flux machine", IEEE International Electric Machine \& Drives Conference 2015,pp.1084-1091

[8] Joachim Schraud, Ewald F.Fuchs, Heidi A.Fuchs, "Experimental Verificationof Critical-Speed Increase of Single phase Induction machine via Winding reconfiguration with Solid switches", IEEE Transaction on Energy Conversion 2008,pp.460-465

[9] J. Schraud and E. F. Fuchs, "Experimental Verification of CriticalSpeed Increase of Induction Machines via Winding Reconfiguration with Solid-State Switches," Submitted to IEEE Transactions on Energy Conversion, Paper No. TEC-00376-2005.

[10] E.F.Fuchs, M.H. Myat, "Speed and Torque range increases of electric drives through compensation of flux weakening", IEEE Conference Publications 2010, pp.1569-1574 